\title{
Relationships between Trait Empathy and Psychological Well-Being in Japanese University Students
}

\author{
Damee Choi ${ }^{1,2^{*}}$, Natsumi Minote ${ }^{3}$, Takahiro Sekiya ${ }^{3}$, Shigeki Watanuki1 \\ ${ }^{1}$ Faculty of Design, Kyushu University, Fukuoka, Japan \\ ${ }^{2}$ Japan Society for the Promotion of Science, Tokyo, Japan \\ ${ }^{3}$ Graduate School of Integrated Frontier Sciences, Kyushu University, Fukuoka, Japan \\ Email: "damee.emma@gmail.com
}

Received 22 June 2016; accepted 16 August 2016; published 19 August 2016

Copyright (C) 2016 by authors and Scientific Research Publishing Inc.

This work is licensed under the Creative Commons Attribution International License (CC BY). http://creativecommons.org/licenses/by/4.0/

(c) $\underset{\mathrm{EY}}{\mathrm{B}}$ Open Access

\section{Abstract}

The Interpersonal Reactivity Index (IRI) is a commonly used instrument for measuring individual differences in trait empathy. It is composed of the following four subscales: Perspective taking; fantasy; empathic concern; and personal distress. Previous studies have reported finding a positive relationship between psychological well-being and perspective taking, but little remains known about the association between psychological well-being and the other IRI subscales. Therefore, in this study, we investigated the degree to which each IRI subscale could predict psychological well-being, which was measured using Ryff's Psychological Well-Being Scales, in 119 Japanese undergraduate and graduate students (43 females, 76 males; mean age: 22 years; age range: 19 25 years). Regression analysis revealed that perspective taking positively predicted personal growth, purpose in life, and environmental mastery, while personal distress negatively predicted autonomy, environmental mastery, and self-acceptance. Neither fantasy nor empathic concern predicted psychological well-being. These results support those found in previous studies, and suggest that perspective taking, a cognitive component of empathy, plays an important role in the improvement of psychological well-being.

\section{Keywords}

Empathy, Psychological Well-Being, Interpersonal Reactivity Index, Perspective Taking, Personal Distress

\footnotetext{
${ }^{*}$ Corresponding author.
}

How to cite this paper: Choi, D., Minote, N., Sekiya, T., \& Watanuki, S. (2016). Relationships between Trait Empathy and Psychological Well-Being in Japanese University Students. Psychology, 7, 1240-1247. 


\section{Introduction}

Empathy is defined as "the ability to imagine oneself in another's place and understand the other's feelings, desires, ideas, and actions" (Encyclopedia Britannica, 1999 edition) and is therefore thought to be an essential component of human social behavior. Previous studies have indicated that empathy is a multidimensional concept (Davis, 1983) which includes both affective and cognitive components. The affective component of empathy is associated with sharing emotions with others, while the cognitive component is associated with taking the perspective of others (reviewed in Decety \& Lamm, 2006, 2009; Zaki \& Ochsner, 2012). The multidimensional facets are also reflected by instruments designed to measure individual differences in empathy. One such example is the Interpersonal Reactivity Index (IRI) (Davis, 1983), one of most widely used questionnaires for measuring trait empathy, which consists of the following four subscales: Perspective taking (trying to adopt the perspective of others); fantasy (identifying with fictional characters); empathic concern (having warm feelings toward and concern for others); and personal distress (feeling anxiety in response to the negative experiences of others). Thus, it is thought that perspective taking represents the cognitive component of empathy, while empathic concern and personal distress represent the affective component of empathy (Dziobek et al., 2008).

Empathy has also been reported to be closely related to psychological well-being (Shanafelt, West, Zhao, Novotny, Kolars, Habermann, \& Sloan, 2005; Thomas, Dyrbye, Huntington, Lawson, Novotny, Sloan, \& Shanafelt, 2007; Wei, Liao, Ku, \& Shaffer, 2011; Manczak, DeLongis, \& Chen, 2015; Boyraz \& Waits, 2015). The definition of well-being varies across studies (for example, hedonic and eudaimonic well-being, Ryan \& Deci, 2001); however, one of the most widely accepted definitions of psychological well-being is "the striving for perfection that represents the realization of one's true potential (Ryff, 1995)". In addition, psychological well-being is related positively with mental health (Jovanović, 2015) and quality of life (Singh \& Junnarkar, 2015). Some studies have found that the perspective taking subscale of the IRI is positively related to mental health (Shanafelt et al., 2005) and quality of life (Thomas et al., 2007), suggesting that cognitive empathy plays an important role in the improvement of psychological well-being. However, the relationship between psychological well-being and the other IRI subscales remains unclear. For example, empathic concern has been shown to be positively related to quality of life (Thomas et al., 2007), but not to mental health (Shanafelt et al., 2005), and some studies that examined the relationship between empathy and psychological well-being measured trait empathy as the sum of perspective taking and empathic concern (Manczak et al., 2015) or of perspective taking, fantasy, and empathic concern (Boyraz \& Waits, 2015).

To the best of our knowledge, the relationship between personal distress and psychological well-being has yet to be examined. Some studies on individual differences in trait empathy have included personal distress as a measure (for example, Jabbi, Swart, \& Keysers, 2007; Choi \& Watanuki, 2014; Choi et al., 2014), while other studies have not (for example, Manczak et al., 2015; Boyraz \& Waits, 2015). This is because empathy and personal distress are thought to be different terms, given that empathy requires a clear distinction between the self and the other, while personal distress does not (reviewed in Decety \& Lamm, 2006, 2009; Singer \& Lamm, 2009). In other words, empathy is "the ability to experience and understand what others feel without confusion between oneself and others" (Decety \& Lamm, 2006). Nonetheless, because personal distress is closely related to emotional contagion, or "primitive empathy" (Hatfield, Rapson, \& Le, 2009), the relationship between personal distress and psychological well-being warrants examination.

Therefore, to gain a better understanding of the relationship between empathy and psychological well-being, the present study aimed to investigate the degree to which each IRI subscale-perspective taking, fantasy, empathic concern, and personal distress - could predict psychological well-being. As an index of psychological well-being, we used Ryff's Psychological Well-Being Scales (PWB) (Ryff, 1989), which consist of the following six subscales: personal growth (feeling of continued improvement of the self); purpose in life (both past and present); autonomy (encompassing self-determination and independence); self-acceptance (possessing a positive attitude toward the self); environmental mastery (controlling external activities and taking advantage of surrounding opportunities); and positive relationships with others (having satisfying and trusting relationships with others). We expected the results of the present study to provide clues regarding which aspects of psychological well-being could be predicted by trait empathy.

\section{Methods}

\subsection{Participants}

The study participants were 119 Japanese undergraduate and graduate students (43 women, 76 men; mean age \pm 
standard deviation: $22.02 \pm 1.35$ years; age range: 19 - 25 years). Participants were selected randomly from students of Kyushu University. All participants provided informed consent after receiving an explanation of the purpose of the study. The study protocol was approved by the ethics committee.

\subsection{Questionnaires}

Participants were asked to complete the following two questionnaires: the Japanese versions of the IRI (Sakurai, 1988) and the PWB (Nishita, 2000). All participants were instructed to read the questionnaire items carefully and choose the responses that best described themselves. Similar to the original, the Japanese version of the IRI is composed of 28 items. The Japanese version of the PWB was modified to comprise 43 items, based on the original (Ryff \& Keys, 1995). All items on the IRI were rated on 4-point Likert scale (1 = "does not describe me very well" to $4=$ "describes me very well"), and all items on the PWB were rated on a 6-point Likert scale ( $1=$ "does not describe me very well" to $6=$ "describes me very well"). We then calculated the scores for each subscale on both the IRI and the PWB, as well as the sum of all items on the PWB.

Examples of items from each of the four IRI subscales are as follows: perspective taking, "I sometimes try to better understand my friends by imagining how things look from their perspective"; fantasy, "After seeing a play or movie, I have felt as though I were one of the characters"; empathic concern, "I often have tender, concerned feelings for people less fortunate than me"; and personal distress, "When I see someone who badly needs help in an emergency, I go to pieces".

Examples of items from each of the six PWB subscales are as follows: Personal growth, "For me, life has been a continuous process of learning, changing, and growing"; purpose in life, "I have a sense of direction and a purpose in life"; autonomy, "My decisions are not typically influenced by what everyone else is doing"; self-acceptance, "In general, I feel confident and positive about myself"; environmental mastery, "I am quite good at managing the many responsibilities of my daily life"; and positive relationships with others, "I know that I can trust my friends, and they know that they can trust me".

\subsection{Statistical Analysis}

Analyses were conducted using SPSS software (Version 17, SPSS Inc., Chicago, IL, USA). First, correlation between IRI and PWB scores were calculated as a preliminary analysis (Pearson correlation coefficient). Second, stepwise regression analyses were conducted with IRI scores (four subscales) as predictor variables and PWB scores (total score and six subscales) as predicted variables. Statistical significance was set at $(p<0.05)$.

\section{Results}

\subsection{Preliminary Analysis}

The mean (and standard deviation) IRI and PWB scores are shown in Table 1. Cronbach's alpha was acceptable

Table 1. Mean scores of Interpersonal Reactivity Index (IRI) and Psychological Well-Being Scale (PWB).

\begin{tabular}{lcccc}
\hline & Mean (SD) & Reliability $^{\mathrm{a}}$ & Age $^{\mathrm{b}}$ & Gender $^{\mathrm{c}}$ \\
\hline Interpersonal Reactivity Index (IRI) & & & & \\
Perspective taking & $2.75(0.48)$ & .761 & .077 & .082 \\
Fantasy & $2.79(0.51)$ & .689 & .017 & .036 \\
Empathic concern & $2.77(0.38)$ & .583 & .120 & -.070 \\
Personal distress & $2.54(0.48)$ & .712 & -.035 & -.000 \\
Psychological Well-Being (PWB) & $4.12(0.48)$ & .920 & .062 & .103 \\
Personal growth & $5.01(0.56)$ & .806 & .080 & .048 \\
Purpose in life & $4.00(0.85)$ & .870 & .079 & .094 \\
Autonomy & $3.61(0.63)$ & .770 & .078 & .094 \\
Self-acceptance & $3.74(0.74)$ & .792 & .039 & .022 \\
Environmental mastery & $4.05(0.61)$ & .831 & .039 & .087 \\
Positive relationships with others & $4.34(0.65)$ & .789 & -.056 & .086 \\
\hline
\end{tabular}

Note: $N=119 . \mathrm{SD}=$ Standard deviation. ${ }^{\mathrm{a} C r o n b a c h}$ 's Alpha. ${ }^{\mathrm{b} C o r r e l a t i o n ~ b e t w e e n ~ a g e ~ a n d ~ t r a i t s . ~}{ }^{\mathrm{c}}$ Correlation between gender and traits $(0=$ male, 1 = female). No significant correlation was shown for age and gender. 
for all IRI and PWB subscales (all $a>0.7)$ except for fantasy ( $a=0.689)$ and empathic concern in the IRI ( $a=$ 0.583). No age- or sex-related effects on IRI or PWB scores were found (all $p>0.05$ ).

The correlations between IRI and PWB scores are shown in Table 2. All data were subjected to regression analysis. Significant and positive intercorrelations were found between all IRI items $(p<0.05)$ except for perspective taking and personal distress $(p=0.344)$, and between all PWB items $(p<0.05)$ except for autonomy and positive relationships with others $(p=0.061)$.

\subsection{Regression Analysis}

The results of stepwise regression analyses are shown in Table 3. The total PWB score was negatively predicted by personal distress and positively predicted by perspective taking. This difference was also evident in the PWB subscales: perspective taking positively predicted personal growth, purpose in life, and environmental mastery, whereas personal distress negatively predicted autonomy, self-acceptance, and environmental mastery. Neither fantasy nor empathic concern predicted psychological well-being. In addition, positive relationships with others was not predicted by any IRI subscale.

\section{Discussion}

The results of the present study revealed that psychological well-being is positively predicted by perspective taking and negatively predicted by personal distress.

\subsection{Effect of Perspective Taking on Psychological Well-Being}

The positive relationship found between perspective taking and psychological well-being in the present study was not high, only accounting for less than $6 \%$ of the variance (Table 3); however, it does suggest that perspective taking plays an important role in psychological well-being, which supports the findings of previous studies (Shanafelt et al., 2005: Thomas et al., 2007). The PWB subscales predicted by perspective taking were personal growth, purpose in life, and environmental mastery. This suggests that perspective taking and psychological well-being might be positively related because perspective taking and the three PWB subscales are associated with cognitive efforts to regulate emotion and behavior. Taking the perspective of others indicates suppression of the perspective of the self, and therefore helps reduce selfish behavior or impulsive emotions through cognitive effort. Moreover, humans can take the perspective of not only others, but also their future selves (Gazzaniga, 2008). This suggests the possibility that perspective taking might help individuals control their behavior or manage their environment to achieve a better future self. This interpretation is also in line with the close relationship between well-being and the cognitive regulation of emotions such as reappraisal (John \& Gross, 2004).

Table 2. Correlations between Interpersonal Reactivity Index (IRI) and Psychological Well-Being Scale (PWB).

\begin{tabular}{|c|c|c|c|c|c|c|c|c|c|c|c|}
\hline & 1. & 2. & 3. & 4. & 5. & 6. & 7. & 8. & 9. & 10. & 11 \\
\hline \multicolumn{12}{|l|}{ Interpersonal Reactivity Index } \\
\hline 1. Perspective taking & - & $.23^{*}$ & $.25^{* *}$ & -.09 & $.22^{*}$ & $.19^{*}$ & $.19^{*}$ & .11 & .04 & $.27^{* *}$ & .13 \\
\hline 2. Fantasy & & - & $.34^{* *}$ & $.25^{* *}$ & -.04 & .02 & -.05 & -.11 & .00 & -.04 & .02 \\
\hline 3. Empathic concern & & & - & .18 & .10 & .14 & .15 & -.08 & .07 & .08 & .07 \\
\hline 4. Personal distress & & & & - & $-.31^{* *}$ & -.13 & -.11 & $-.38^{* *}$ & $-.32^{* *}$ & $-.30^{* *}$ & -.10 \\
\hline \multicolumn{12}{|l|}{ Psychological Well-being } \\
\hline 5. Total score & & & & & - & $.71^{* *}$ & $.78^{* *}$ & $.55^{* *}$ & $.74^{* *}$ & $.74^{* *}$ & $.68^{* *}$ \\
\hline 6. Personal growth & & & & & & - & $.54^{* *}$ & $.24^{* *}$ & $.33^{* *}$ & $.50^{* *}$ & $.47^{* *}$ \\
\hline 7. Purpose in life & & & & & & & - & $.33^{* *}$ & $.51^{* *}$ & $.43^{* *}$ & $.36^{* *}$ \\
\hline 8. Autonomy & & & & & & & & - & $.32^{* *}$ & $.32^{* *}$ & .17 \\
\hline 9. Self-acceptance & & & & & & & & & - & $.47^{* *}$ & $.43^{* *}$ \\
\hline 10. Environmental mastery & & & & & & & & & & - & $.46^{* *}$ \\
\hline 11. Positive relationships with others & & & & & & & & & & & - \\
\hline
\end{tabular}

Note: $N=119$. Pearson correlation. ${ }^{*} p<.05,{ }^{* *} p<.01$. 
Table 3. Results of stepwise regression analyses with Interpersonal Reactivity Index (IRI) as predictor variables and Psychological Well-Being Scale (PWB) as predicted variables.

\begin{tabular}{|c|c|c|c|c|}
\hline & & $\Delta R^{2}$ & $\beta$ & $\mathrm{sr}^{2}$ \\
\hline \multicolumn{5}{|l|}{ Total score } \\
\hline \multirow[t]{2}{*}{ Model 1} & & $.096^{* *}$ & & \\
\hline & Personal distress & & $-.310^{* *}$ & .10 \\
\hline \multirow[t]{3}{*}{ Model 2} & & $.036^{* * *}$ & & \\
\hline & Personal distress & & $-.294^{* *}$ & .09 \\
\hline & Perspective taking & & $.190^{*}$ & .04 \\
\hline \multicolumn{5}{|l|}{ Personal growth } \\
\hline \multirow[t]{2}{*}{ Model 1} & & $.034^{*}$ & & \\
\hline & Perspective taking & & $.185^{*}$ & .03 \\
\hline \multicolumn{5}{|l|}{ Purpose in life } \\
\hline \multirow[t]{2}{*}{ Model 1} & & $.036^{*}$ & & \\
\hline & Perspective taking & & $.189^{*}$ & .04 \\
\hline \multicolumn{5}{|l|}{ Autonomy } \\
\hline \multirow[t]{2}{*}{ Model 1} & & $.145^{* * *}$ & & \\
\hline & Personal distress & & $-.381^{* * *}$ & .15 \\
\hline \multicolumn{5}{|l|}{ Self-acceptance } \\
\hline \multirow[t]{2}{*}{ Model 1} & & $.102^{* * *}$ & & \\
\hline & Personal distress & & $-.319^{* * *}$ & .10 \\
\hline \multicolumn{5}{|c|}{ Environmental mastery } \\
\hline \multirow[t]{2}{*}{ Model 1} & & $.092^{* *}$ & & \\
\hline & Personal distress & & $-.304^{* *}$ & .09 \\
\hline \multirow[t]{3}{*}{ Model 2} & & $.059^{* * *}$ & & \\
\hline & Personal distress & & $-.282^{* *}$ & .08 \\
\hline & Perspective taking & & $.245^{* *}$ & .06 \\
\hline
\end{tabular}

Note: $N=119 .{ }^{*} p<0.05, \stackrel{* *}{p}<<0.01, \stackrel{* * *}{p}<0.001$.

\subsection{Effect of Fantasy and Empathic Concern on Psychological Well-Being}

As mentioned in the introduction, previous studies have reported different results regarding the association between empathic concern and psychological well-being (Shanafelt et al., 2005; Thomas et al., 2007). No association was found between empathic concern and psychological well-being in the present study, suggesting the absence of a relationship between psychological well-being and having warm feelings and compassion for others; this supports the findings reported by Shanafelt et al. (2005). Specifically, given that both empathic concern and positive relationships with others reflect concern for others, it is interesting that empathic concern did not predict positive relationships with others. This might be due to differences between the two subscales, in that empathic concern tends to focus on emotional responses (e.g., feeling sorry for or sympathy toward others), while positive relationships with others tends to focus more on actual behaviors (e.g., enjoying conversation with others). In addition, empathic concern reflects responses to others in "negative" situations (i.e., unfortunate others), while positive relationships with others does not specifically depend on whether others are in a "negative" or a "positive" situation. Taken together, the findings of the present study that empathic concern is not associated with positive relationships with others suggests that emotional responses such as sympathy for others in negative situations do not have a direct effect on the development of positive relationships with others.

Furthermore, the absence of an association between psychological well-being and fantasy also suggests the lack of a relationship between psychological well-being and the trait of becoming immersed in a fictional character. This might be because the object of immersion reflected in the fantasy subscale is "fictional" and there- 
fore not reality. However, the relationship between psychological well-being and the fantasy subscale of the IRI remains unclear, and further studies are needed to confirm this result.

\subsection{Effect of Personal Distress on Psychological Well-Being}

We found that personal distress negatively predicted psychological well-being-specifically, autonomy, environmental mastery, and self-acceptance. As mentioned in the introduction, one of important differences between empathy and personal distress is that empathy requires a clear distinction between the self and the other, while personal distress does not (reviewed in Decety \& Lamm, 2006, 2009; Singer \& Lamm, 2009). Therefore, a blurred distinction between the self and the other seems to be associated with less independence, a decreased ability to control the self and the environment, and a more negative attitude toward the self. This reconfirms the importance of the cognitive aspect of empathy for the improvement of psychological well-being as mentioned above, since distinction between the self and the other requires cognitive effort. In addition, it is worthwhile to emphasize that personal distress negatively predicted self-acceptance. Self-acceptance has been the most frequently mentioned criterion of well-being and is closely related to mental health (Ryff, 1989). Furthermore, previous studies have indicated that personal distress is closely related with depression ( $\mathrm{O}^{\prime} \mathrm{Connor}$, Berry, Weiss, \& Gilbert, 2002; Thoma, Zalewski, von Reventlow, Norra, Juckel, \& Daum, 2011), neuroticism (Bartholow, Sestir, \& Davis, 2005; Lee, 2009), and alexithymia (Grynberg, Luminet, Corneille, Grèzes, \& Berthoz 2010). Taken together, personal distress is thought to be an effective indicator of mental health.

\subsection{Limitations and Future Direction}

The present study did have several limitations. First, the sample size was quite small. Second, the reliability of fantasy and empathic concern was low. Future studies are therefore needed to reexamine the present findings.

In addition, the opposite effects of perspective taking and personal distress on psychological well-being poses the question of whether individuals with a high level of personal distress can improve their psychological well-being by making a cognitive effort to take the perspective of others. Furthermore, regarding the relationship between empathy and psychological well-being, whether empathy predicts not only psychological well-being, but also objective status of well-being (e.g., maintaining a number of close friends or a good relationship with the family) remains unclear. These issues will need to be addressed in future studies in order to clarify the relationship between empathy and well-being.

\section{Conclusion}

The present study found that psychological well-being is positively predicted by perspective taking and negatively predicted by personal distress. In addition, neither fantasy nor empathic concern predicted psychological well-being. These findings suggest the importance of the cognitive aspect of empathy (perspective taking) for the improvement of psychological well-being. To gain a better understanding of the relationship between empathy and psychological well-being, additional studies with larger samples are needed.

\section{Acknowledgements}

The authors sincerely thank the participants of the study.

\section{References}

Bartholow, B. D., Sestir, M. A., \& Davis, E. B. (2005). Correlates and Consequences of Exposure to Video Game Violence: Hostile Personality, Empathy, and Aggressive Behavior. Personality and Social Psychology Bulletin, 31, 1573-1586. http://dx.doi.org/10.1177/0146167205277205

Boyraz, G., \& Waits, J. B. (2015). Reciprocal Associations among Self-Focused Attention, Self-Acceptance, and Empathy: A Two-Wave Panel Study. Personality and Individual Differences, 74, 84-89. http://dx.doi.org/10.1016/j.paid.2014.09.042

Choi, D., \& Watanuki, S. (2014). Effect of Empathy Trait on Attention to Faces: An Event-related Potential (ERP) Study. Journal of Physiological Anthropology, 33, 4. http://dx.doi.org/10.1186/1880-6805-33-4

Choi, D., Nishimura, T., Motoi, M., Egashira, Y., Matsumoto, R., \& Watanuki, S. (2014). Effect of Empathy Trait on Attention to Various Facial Expressions: Evidence from N170 and Late Positive Potential (LPP). Journal of Physiological Anthropology, 33, 18. http://dx.doi.org/10.1186/1880-6805-33-18 
Davis, M. H. (1983). Measuring Individual Differences in Empathy: Evidence for a Multidimensional Approach. Journal of Personality and Social Psychology, 44, 113-126. http://dx.doi.org/10.1037/0022-3514.44.1.113

Decety, J., \& Lamm, C. (2006). Human Empathy through the Lens of Social Neuroscience. The Scientific World Journal, 6 , 1146-1163. http://dx.doi.org/10.1100/tsw.2006.221

Decety, J., \& Lamm, C. (2009). Empathy versus Personal Distress: Recent Evidence from Social Neuroscience. In J. Decety \& W. Ickes (Eds.), The Social Neuroscience of Empathy (pp. 199-214). Cambridge, UK: MIT Press. http://dx.doi.org/10.7551/mitpress/9780262012973.003.0016

Dziobek, I., Rogers, K., Fleck, S., Bahnemann, M., Heekeren, H. R., Wolf, O. T., \& Convit, A. (2008). Dissociation of Cognitive and Emotional Empathy in Adults with Asperger Syndrome Using the Multifaceted Empathy Test (MET). Journal of Autism and Developmental Disorders, 38, 464-473. http://dx.doi.org/10.1007/s10803-007-0486-X

Gazzaniga, M. (2008). Human: The Science behind What Makes Us Nnique. New York: HarperCollins.

Grynberg, D., Luminet, O., Corneille, O., Grèzes, J., \& Berthoz, S. (2010). Alexithymia in the Interpersonal Domain: A General Deficit of Empathy? Personality and Individual Differences, 49, 845-850.

http://dx.doi.org/10.1016/j.paid.2010.07.013

Hatfield, E., Rapson, R. L., \& Le, Y. L. (2009). Emotional Contagion and Empathy. In J. Decety \& W. Ickes (Eds.), The Social Neuroscience of Empathy. Cambridge, MA: MIT. http://dx.doi.org/10.7551/mitpress/9780262012973.003.0003

Jabbi, M., Swart, M., \& Keysers, C. (2007). Empathy for Positive and Negative Emotions in the Gustatory Cortex. Neuroimage, 34, 1744-1753. http://dx.doi.org/10.1016/j.neuroimage.2006.10.032

John, O. P., \& Gross, J. J. (2004). Healthy and Unhealthy Emotion Regulation: Personality Processes, Individual Differences, and Life Span Development. Journal of Personality, 72, 1301-1334. http://dx.doi.org/10.1111/j.1467-6494.2004.00298.x

Jovanović, V. (2015). Structural Validity of the Mental Health Continuum-Short Form: The Bifactor Model of Emotional, Social and Psychological Well-Being. Personality and Individual Differences, 75, 154-159.

http://dx.doi.org/10.1016/j.paid.2014.11.026

Lee, S. A. (2009). Does Empathy Mediate the Relationship between Neuroticism and Depressive Symptomatology among College Students? Personality and Individual Differences, 47, 429-433. http://dx.doi.org/10.1016/j.paid.2009.04.020

Manczak, E. M., DeLongis, A., \& Chen, E. (2015). Does Empathy Have a Cost? Diverging Psychological and Physiological Effects within Families. Health Psychology, 35, 211-218. http://dx.doi.org/10.1037/hea0000281

Nishita, Y. (2000). Diverse Life-Styles and Psychological Well-Being in Adult Women. Japanese Journal of Educational Psychology, 48, 433-443. (In Japanese with English Abstract). http://dx.doi.org/10.5926/jjep1953.48.4 433

O’Connor, L. E., Berry, J. W., Weiss, J., \& Gilbert, P. (2002). Guilt, Fear, Submission, and Empathy in Depression. Journal of Affective Disorders, 71, 19-27. http://dx.doi.org/10.1016/S0165-0327(01)00408-6

Ryan, R. M., \& Deci, E. L. (2001). On Happiness and Human Potentials: A Review of Research on Hedonic and Eudaimonic Well-Being. Annual Review of Psychology, 52, 141-166. http://dx.doi.org/10.1146/annurev.psych.52.1.141

Ryff, C. D. (1989). Happiness Is Everything, or Is It? Explorations on the Meaning of Psychological Well-Being. Journal of Personality and Social Psychology, 57, 1069-1081. http://dx.doi.org/10.1037/0022-3514.57.6.1069

Ryff, C. D. (1995). Psychological Well-Being in Adult Life. Current Directions in Psychological Science, 4, 99-104. http://dx.doi.org/10.1111/1467-8721.ep10772395

Ryff, C. D., \& Keyes, C. L. M. (1995). The Structure of Psychological Well-Being Revisited. Journal of Personality and Social Psychology, 69, 719-727. http://dx.doi.org/10.1037/0022-3514.69.4.719

Sakurai, S. (1988). The Relationship between Empathy and Helping Behavior in College Students. Bulletin of Nara University of Education, 37, 149-154. (In Japanese with English abstract).

Shanafelt, T. D., West, C., Zhao, X., Novotny, P., Kolars, J., Habermann, T., \& Sloan, J. (2005). Relationship between Increased Personal Well-Being and Enhanced Empathy among Internal Medicine Residents. Journal of General Internal Medicine, 20, 559-564. http://dx.doi.org/10.1007/s11606-005-0102-8

Singer, T., \& Lamm, C. (2009). The Social Neuroscience of Empathy. Annals of the New York Academy of Sciences, 1156, 81-96. http://dx.doi.org/10.1111/j.1749-6632.2009.04418.x

Singh, K., \& Junnarkar, M. (2015). Correlates and Predictors of Positive Mental Health for School Going Children. Personality and Individual Differences, 76, 82-87. http://dx.doi.org/10.1016/j.paid.2014.11.047

Thoma, P., Zalewski, I., von Reventlow, H. G., Norra, C., Juckel, G., \& Daum, I. (2011). Cognitive and Affective Empathy in Depression Linked to Executive Control. Psychiatry Research, 189, 373-378.

http://dx.doi.org/10.1016/j.psychres.2011.07.030

Thomas, M. R., Dyrbye, L. N., Huntington, J. L., Lawson, K. L., Novotny, P. J., Sloan, J. A., \& Shanafelt, T. D. (2007). How Do Distress and Well-Being Relate to Medical Student Empathy? A Multicenter Study. Journal of General Internal 
Medicine, 22, 177-183. http://dx.doi.org/10.1007/s11606-006-0039-6

Wei, M., Liao, K. Y. H., Ku, T. Y., \& Shaffer, P. A. (2011). Attachment, Self-Compassion, Empathy, and Subjective WellBeing among College Students and Community Adults. Journal of Personality, 79, 191-221. http://dx.doi.org/10.1111/j.1467-6494.2010.00677.x

Zaki, J., \& Ochsner, K. N. (2012). The Neuroscience of Empathy: Progress, Pitfalls and Promise. Nature Neuroscience, 15, 675-680. http://dx.doi.org/10.1038/nn.3085

Submit or recommend next manuscript to SCIRP and we will provide best service for you:

Accepting pre-submission inquiries through Email, Facebook, LinkedIn, Twitter, etc.

A wide selection of journals (inclusive of 9 subjects, more than 200 journals)

Providing 24-hour high-quality service

User-friendly online submission system

Fair and swift peer-review system

Efficient typesetting and proofreading procedure

Display of the result of downloads and visits, as well as the number of cited articles

Maximum dissemination of your research work

Submit your manuscript at: http://papersubmission.scirp.org/ 